\title{
Crossing the Atlantic: Integrating cross-cultural experiences into undergraduate business courses using virtual communities technology
}

\author{
Denise J. Luethge, David Raska, Bertie M. Greer \& Christina O'Connor
}

To cite this article: Denise J. Luethge, David Raska, Bertie M. Greer \& Christina O'Connor (2016) Crossing the Atlantic: Integrating cross-cultural experiences into undergraduate business courses using virtual communities technology, Journal of Education for Business, 91:4, 219-226, DOI: 10.1080/08832323.2016.1160022

To link to this article: https://doi.org/10.1080/08832323.2016.1160022

\section{曲 Published online: 30 Mar 2016.}

\section{Submit your article to this journal $\llbracket$}

Џlll Article views: 192

View Crossmark data ¿

Citing articles: 3 View citing articles 5 


\title{
Crossing the Atlantic: Integrating cross-cultural experiences into undergraduate business courses using virtual communities technology
}

\author{
Denise J. Luethge ${ }^{a, b}$, David Raska ${ }^{a}$, Bertie M. Greer ${ }^{a}$, and Christina O'Connor ${ }^{c}$ \\ ${ }^{a}$ Northern Kentucky University, Highland Heights, Kentucky, USA; ${ }^{b}$ Doshisha University, Kyoto, Japan; ${ }^{c}$ Maynooth University, Maynooth, Ireland
}

ABSTRACT

Today's business school academics are tasked with pedagogy that offers students an understanding of the globalization of markets and the cross-cultural communication skills needed in today's business environment. The authors describe how a virtual cross-cultural experience was integrated into an undergraduate business course and used as an innovative pedagogical tool to give students and faculty an opportunity to build cross-cultural communication skills and develop cultural knowledge in ways similar to more costly travel abroad experiences. This experience contributes to competent and globally minded business graduates and faculty who are fit for the challenges of the global marketplace.

\section{KEYWORDS}

cross-cultural experiences; cultural sensitivity; digital and social media; virtual communities
Globalization requires that individuals from diverse cultures are able to work together effectively (Javidan, 2013). As a result, it is important that business leaders of the 21st century have the global competency to work with people from a wide variety of cultures, understand and accept different viewpoints, and communicate well with individuals from different backgrounds (Duus \& Cooray, 2014; Stahl \& Brannen, 2013; Taras et al., 2013). Given the importance of cross-cultural competency in the business world, it is essential that business education today offer students the opportunity to learn the skills necessary to function effectively in this multicultural workplace (Erez et al., 2013; Javidan, 2013; Mendenhall, Arnardottir, Oddou, \& Burke, 2013; Taras et al., 2013). Developing and integrating cross-cultural experiences that improve students' cultural knowledge, intercultural competency and awareness of cultural biases has become extremely important in developing effective business curriculum (Demangeot et al., 2013; Johnson \& Mader, 1992; Koenig, 2007; Metcalf, 2013; Tanner, 2002), especially one that is aligned with the needs of the real world (Aistrich, Saghafi, \& Sciglimpaglia, 2006) and designed to provide students with competitive advantages (Hopkins, Raymond, \& Carlson, 2011). Some of the most important skills we can help our students develop are their ability to work, communicate and influence individuals from multiple cultures (Deardorff, 2006; MacNab, 2012; Maznevski, 2013).

In an effort to increase this competency, we introduce the virtual cross-cultural experience (VCCE) as an innovative pedagogical tool for improving student's ability to effectively participate in multicultural work tmeetings facilitated through web-enabled virtual technologies (e.g., Skype, WhatsApp, WebEx) that allow students in one country to hold virtual meetings with students from a different country over the Internet in real time and without travel. Virtual technologies enable students to see each other, hear each other and work together as a global virtual team (GVT). In this study we explored how to effectively implement a VCCE in a business course and share insights that can be gained from the VCCE implementation process for both faculty and students.

\section{Global virtual teams}

As students will be working in a GVT, it is important to briefly note the advantages and challenges they may face when put into this environment. First, a GVT can be defined as a team where members come from two or more different countries, different physical locals, and often different time zones, requiring the teams to use technology-assisted communication tools (Baba, Gluesing, Ratner, \& Wagner, 2004; Brandl \& Neyer, 2009; Dekker, Rutte, \& Van den Berg, 2008; Erez et al., 2013). A number of studies have examined the advantages associated with GVTs, such as the use of a global base to connect and coordinate the talent and skill base of a worldwide team, resulting in savings from both time and

CONTACT Denise J. Luethge luethged1@nku.edu Northern Kentucky University, Haile/U.S. Bank College of Business, Department of Management, Highland Heights, KY 41076, USA. 
travel while increasing flexibility for the organization (Dekker, Rutte, \& Van den Berg, 2008; Ferreira, Pinheiro de Lima, \& Gouvea da Costa, 2012; Furst, Blackburn, \& Rosen, 2001). In addition, GVTs provide the opportunity for 24 hour work cycles, as projects are handed off from one individual to another (Magnusson, Schuster, \& Taras, 2014). Finally, Stahl, Maznevski, Voight, and Jonsen (2010) noted that culturally diverse teams, such as those found in GVTs, are more likely to experience the advantages of increased creativity, greater satisfaction, lower conflict and higher social integration than teams that are not dispersed. Despite these advantages, there are also a number of challenges for GVTs, many of which can be traced to cross-cultural differences and the problems that can result. For example, miscommunication resulting either from differences in culture or from the inability to grasp nonverbal cues are common among GVTs (Cramton \& Hinds, 2014; Daim et al., 2012; Klitmøller \& Lauring, 2013; Rosen, Furst, \& Blackburn, 2007; Shachaf, 2008). In addition, GVTs also can be challenged by a lack of shared norms, and coupled with differences in time zones, can make forming a common culture difficult (Cramton \& Hinds, 2014; Jarvenpaa \& Leidner, 1999; Magnusson et al., 2014; Mockaitis, Rose, \& Zettinig, 2009).

The present innovation, the VCCE, was designed to accomplish immersion into another culture at a low cost to students, faculty, and colleges by facilitating cross-cultural experiences via widely used virtual communities technology such as Skype, WhatsApp, and WebEx. These technologies allow users to interact across geographical boundaries and can serve to enhance students' perceived value of cross-cultural experiences and intercultural sensitivity in ways similar to those accorded through travel abroad experiences. We believe the VCCE is an alternative, rather than a substitute, for a study abroad experience.

\section{Integration of VCCE into the business course curricula}

The VCCE requires connecting two or more classrooms, each in a different country. The same project is assigned in both classrooms to teams consisting of students from both countries. In the present case, the two instructors, one from the United States and one from Ireland, were introduced by a U.S. colleague who also had an interest in VCCE projects. Most higher education institutions have well-established partnerships with other higher education institutions around the world, thus, developing these partnerships is typically not difficult. Furthermore, many instructors have colleagues at various institutions around the world that they have met through their scholarly and teaching activities. Together, these existing partnerships provide an ideal option as a starting point for identifying instructors or courses that would be appropriate for VCCE. For the VCCE to be effective, there must be faculty teaching courses that have a suitable assignment that would require students to meaningfully cooperate with students in a different country in order to complete the assignment, such as a high level project. In our case, two marketing faculty and their courses at both institutions were identified as compatible to enable this cooperation. The end result was the development of a research project and an exchange between the two universities.

In business courses, there are many types of assignments (e.g., projects, presentations, exercises) that provide opportunities for integration using a VCCE ranging from simple, less time intensive to highly complex, more time intensive projects. The project used in this paper demonstrates a more complex assignment; a client-based project that is commonly used in marketing classrooms for facilitating active learning (Lopez \& Lee, 2005; Metcalf, 2013; Parsons \& Lepkowska-White, 2009; Raska, Keller, \& Shaw, 2013). This project was completed by teams of students from two different marketing courses in two different countries: 101 students enrolled in an international marketing course at a university in Ireland and 34 students enrolled in global and cultural issues in marketing at a university in the United States. Each team consisted of three to five Irish students and two U.S. students who completed the project in fall 2013 semester. The integration of VCCE was executed in two phases, the VCCE planning phase and the VCCE execution phase. In the next section we describe how the two classes were integrated, in terms of planning and execution.

\section{Project description}

\section{Phase 1: Planning phase}

The main objective of the planning phase was to integrate the project into both classes and to plan the general structure of activities for the actual VCCE project prior to the beginning of the semester. This phase was especially important due to the existing constraints of differences in class structures and general university policies. The basic similarities and differences between the two courses are summarized in Table 1 . We wanted to ensure that VCCE would be integrated without major changes to the classes, and that the experience would not result in excessive workload for either the students or the instructors. The planning phase 1 was completed in three steps and is summarized in Table 2. 
Table 1. Course descriptions.

\begin{tabular}{|c|c|c|}
\hline Characteristic & United States & Ireland \\
\hline Location & United States & Ireland \\
\hline Time zone & UTC-05:00 (Eastern Time Zone) & UTC+00:00 (Greenwich Time Zone) \\
\hline Course & Global and cultural issues in marketing & International marketing \\
\hline Class meeting time & Tuesday/Thursday 9:25-10:40 & Tuesday 12:00-2:00 \\
\hline Number of students & 31 & 101 \\
\hline Number of teams & 15 & 15 mixed and 7 all Irish groups \\
\hline Semester duration & August 20-December 12 & September 16-December 20 \\
\hline Exam weight & $40 \%$ & $60 \%$ \\
\hline Project weight & $40 \%$ (no word limits) & $40 \%$ (word limits) \\
\hline Other & $20 \%$ & \\
\hline VCCE deliverables & $\begin{array}{l}\text { Team Project (10\%) focusing on identifying marketing } \\
\text { problem's solutions based on the outcomes of SWOT } \\
\text { analysis, presented as a three page summary with one } \\
\text { page as a team profile. } \\
\text { Individual Project (10\%) focusing on developing target } \\
\text { marketing strategies for the U.S. and Irish markets } \\
\text { designed to solve the problem, presented as a two } \\
\text { page summary. } \\
\text { Individual Project ( } 20 \% \text { ) focusing on developing marketing } \\
\text { mix strategies for the U.S. and Irish markets designed to } \\
\text { solve the problem, presented as a two-page summary. }\end{array}$ & $\begin{array}{l}\text { Individual Project (40\%) focusing on developing } \\
\text { marketing plan for the U.S. and Irish markets } \\
\text { and submitted as a 15-page limit paper. }\end{array}$ \\
\hline
\end{tabular}

\section{Step 1: VCCE ideas}

The first step required the instructors (authors C.O. and D.R.) to collaborate via Skype and discuss the basics of VCCE and how it could be integrated in their courses (see Table 2). During this step, each of the instructors agreed to generate ideas about how VCCE could be integrated and shared those ideas via a shared DropBox folder prior to execution of Step 2. The focus was mainly on assignments and integration. The outcome of this step was a list of ideas that the instructors deemed as appropriate for themselves and for each of the courses.

\section{Step 2: Scope of VCCE assignment}

Building on the list generated in Step 1, the instructors discussed the most viable and exciting ideas for their classes. In this case, one of the instructors had the opportunity to complete a client-based project for a consumer goods company with operations around the world, including the United States and Ireland. In this project, the client needed to obtain insights about how to improve consumers' commitment to washing laundry in cold water as a means for achieving its global sustainability goals. Consequently, it became the context for VCCE. As each instructor was constrained by his or her own class requirements and institutional policies, they decided to agree on one set of learning objectives that would facilitate VCCE. In addition, they agreed that the deliverables would be determined by each instructor separately (for a basic description of the deliverables, see Table 1).

\section{Step 3: VCCE schedule}

The last step in the planning phase was to agree on the number of student VCCE meetings and their goals and to provide rationale for each of the meetings and how they relate to the expected deliverables. The instructors decided to engage students in four meetings, spread over a four-week period during the fall semester, with all meetings completed prior to students' submission of the deliverables. In this step, it was important that meetings were scheduled at the time that suited the class calendar

Table 2. Overview of phase 1: VCCE planning.

\begin{tabular}{|c|c|c|c|}
\hline & Step & Goal & Outcome \\
\hline 1 & Ideas & $\begin{array}{l}\text { Instructors: Brainstorm about what assignments } \\
\text { might be appropriate for VCCE integration via virtual meeting. }\end{array}$ & $\begin{array}{l}\text { Instructors: Instructor A generates a list of ideas and } \\
\text { shares it with Instructor B via Dropbox. Instructor B } \\
\text { updates the list prior to Step P2. }\end{array}$ \\
\hline 2 & $\begin{array}{l}\text { Scope of } \\
\text { assignment }\end{array}$ & $\begin{array}{l}\text { Instructors: Agree on the idea that fits both instructors and } \\
\text { discuss its scope within the constraints of each course via virtual meeting. }\end{array}$ & $\begin{array}{l}\text { Instructors: Instructor B creates description of the } \\
\text { assignment scope and shares it with Instructor A via } \\
\text { Dropbox. Instructor A updates prior to Step P3. }\end{array}$ \\
\hline 3 & Schedule & $\begin{array}{l}\text { Instructors: Agree on the scope and then discuss } \\
\text { schedule of meetings that fits both courses via virtual meeting. }\end{array}$ & $\begin{array}{l}\text { Instructors: Instructor A develops schedule shares it with } \\
\text { Instructor B via Dropbox. Instructor B updates prior } \\
\text { to commencing classes. }\end{array}$ \\
\hline
\end{tabular}


to ensure students were provided with the knowledge they needed to complete the meetings' goal. For example, assessment of strengths, weaknesses, opportunities and threats (SWOT analysis) had to be discussed in each course prior to expecting a deliverable (see Table 2). The U.S. students would present their findings to the Irish students in Week 7. As a result, SWOT analyses had to be discussed in the U.S. class a reasonable amount of time prior to Week 7. In contrast, the Irish students presented their results during their Week 3 (their semester started later in the academic calendar). As such, the Irish instructor had to make slight adjustments to make sure SWOT analyses were covered during the first three weeks of the class. Finally, the instructors also agreed that they would meet with students to discuss the project and how students were performing on an as-needed basis via e-mail, Skype, WhatsApp, or WebEx.

\section{Phase 2: VCCE project execution phase}

The main objective of this phase was to execute VCCE in both classes within the scope and schedule as defined earlier. This phase was executed in four steps and is summarized in Table 3.

\section{Step 1: VCCE project launch}

The projects with integrated VCCE were presented to students at the U.S. and Ireland institutions during their regular class time in Week 5 and Week 1, respectively. The instructions focused on achieving the predefined learning objectives (see planning phase Step 2) and were discussed in the classroom, followed by an open question forum to address any concerns. Students were also given project instructions, including a VCCE meeting schedule, via their class websites. The instructions included

Table 3. Overview of phase 2: VCCE execution.

\begin{tabular}{|c|c|c|c|c|}
\hline Step & & $\begin{array}{c}\text { Date } \\
\text { (United States/Ireland) }\end{array}$ & Goal & Outcome \\
\hline 1 & Project launch & Week 5/1 & $\begin{array}{l}\text { Instructors: Introduce scope of project with VCCE } \\
\text { meetings to students in the class and make } \\
\text { information available on course websites. }\end{array}$ & $\begin{array}{l}\text { Instructors: Meet on per need basis.Students: } \\
\text { Read project instructions, including meeting } \\
\text { schedule and be ready to ask questions, if } \\
\text { needed. }\end{array}$ \\
\hline 2 & Teams & Week 6/2 & $\begin{array}{l}\text { Instructors: Assist students in creating teams and } \\
\text { team captains.Students: Create teams, assign } \\
\text { team captains, exchange contact information, } \\
\text { and agree on the first meeting time and day } \\
\text { options. }\end{array}$ & $\begin{array}{l}\text { Instructors: Instructor A develops a list of teams } \\
\text { with e-mails and shares it with Instructor B } \\
\text { via Dropbox. Instructor B updates the list. } \\
\text { Both instructors share appropriate e-mails } \\
\text { with team captains.Students: Team captains } \\
\text { initiate contact with foreign counterparts } \\
\text { via e-mails provided by the instructors to } \\
\text { establish contact and agree on time and day } \\
\text { for VCCE meeting } 1 .\end{array}$ \\
\hline \multirow[t]{4}{*}{3} & \multirow[t]{4}{*}{ Meetings } & Week $7 / 3$ & $\begin{array}{l}\text { Students: Meet at their scheduled time to learn } \\
\text { about each other, obtain information } \\
\text { required for project deliverable, and agree on } \\
\text { meeting times/dates going forward. }\end{array}$ & $\begin{array}{l}\text { Students: Create team profile for their project } \\
\text { deliverable. }\end{array}$ \\
\hline & & Weeks $7 / 3-14 / 10$ & $\begin{array}{l}\text { Instructors: Reminds students to work on their } \\
\text { projects. }\end{array}$ & Instructors: Meet on per need basis. \\
\hline & & Week $8 / 4$ and $9 / 5$ & $\begin{array}{l}\text { Students: U.S. students' execute SWOT analysis of } \\
\text { client's washing product brand X in the } \\
\text { United States and present results to Irish } \\
\text { team at their scheduled time. }\end{array}$ & $\begin{array}{l}\text { Students: U.S. students create SWOT analysis } \\
\text { summary for their project deliverable and } \\
\text { share it with Irish students, if desired. }\end{array}$ \\
\hline & & Week 10/6 & $\begin{array}{l}\text { Students: Discuss ideas about marketing } \\
\text { strategies for solving the problem in the light } \\
\text { of SWOT analysis at their scheduled time. }\end{array}$ & $\begin{array}{l}\text { Students: U.S. and Irish students summarize } \\
\text { their ideas and share them with each other. }\end{array}$ \\
\hline \multirow[t]{4}{*}{4} & \multirow[t]{4}{*}{ Projects } & Week 11/7 & $\begin{array}{l}\text { Students: U.S. students work on team project } \\
\text { focusing on identifying marketing problem's } \\
\text { solutions based on the outcomes of SWOT } \\
\text { analysis. }\end{array}$ & $\begin{array}{l}\text { Students: U.S. students complete and submit } \\
\text { team project to the instructor and share it } \\
\text { with Irish students. }\end{array}$ \\
\hline & & Week 12/8 & $\begin{array}{l}\text { Students: U.S. students work on individual project } \\
\text { focusing on developing target marketing } \\
\text { strategies for the U.S. and Irish markets } \\
\text { designed to solve the problem. }\end{array}$ & $\begin{array}{l}\text { Students: U.S. students complete and submit } \\
\text { individual project. Sharing and meetings } \\
\text { with Irish students are optional. }\end{array}$ \\
\hline & & Week 13/9 & $\begin{array}{l}\text { Students: Irish students work on individual } \\
\text { projects focusing on developing marketing } \\
\text { plans for the U.S. and Irish markets designed } \\
\text { to solve the problem. }\end{array}$ & $\begin{array}{l}\text { Students: Irish students complete and submit } \\
\text { individual project. Sharing and meetings } \\
\text { with U.S. students are optional. }\end{array}$ \\
\hline & & Week 14/10 & $\begin{array}{l}\text { Students: U.S. students work on individual project } \\
\text { focusing on developing marketing mix } \\
\text { strategies for the U.S. and Irish markets } \\
\text { designed to solve the problem. }\end{array}$ & $\begin{array}{l}\text { Students: U.S. students complete and submit } \\
\text { individual project. Sharing and meetings } \\
\text { with Irish students are optional. }\end{array}$ \\
\hline
\end{tabular}


information about the platforms to be used to conduct meetings (e.g., Skype, WebEx, WhatsApp) and provided students with technical support information. ${ }^{1}$ Notably, the instructors did not delve into details of the project during initial class meetings to avoid overwhelming students with too much information. Instead, the instructors only presented the elements students needed to know at that time. Furthermore, the instructors did not describe the topics to be discussed at each meeting. Instead, they focused on the learning objectives and how students would use the insights from their counterparts to achieve these objectives.

\section{Step 2: VCCE teams}

The teams were created during Week 6 (United States) and Week 2 (Ireland), respectively. First, the U.S. instructor asked students $(n=31)$ to form teams of two (with one team having three members) and select one of the members to be team captain. The team captains were then used as a primary point of contact to simplify scheduling and realization of meetings. Once formed, the U.S. instructor shared the list, including email addresses, with Irish instructor. Following the same procedure, the Irish instructor assisted students $(n=101)$ to form their teams of three to five students. Of the 101 Irish students participating in the study, 31 Irish students formed seven completely all Irish Groups. Each all-Irish group comprised 4-5 members. ${ }^{2}$ Once the teams were formed, team captains on both sides were provided with e-mail addresses of their team counterparts and asked to initiate the first contact to introduce themselves and exchange contact information. Instructors used class meetings to check on students and their progress communicating with their out-of-country team members.

\section{Step 3: VCCE meetings}

As summarized in Table 3, the instructors provided students with goals for each meeting in the assignment instructions. The first meeting was used to reduce anxiety; therefore, students were asked to use the meeting to get to know each other and obtain personal information needed prior to completing project deliverables (e.g., nicknames, ages, interests, unique features, dream jobs). Furthermore, students were asked to schedule their own future meeting times to ensure their personal schedules and the 5-hr time difference was considered. The remaining three meetings followed over the next threeweek period with each producing information students needed to complete the project deliverables for each of the classes. Given the differences in the academic calendars between the universities in Ireland and the United States and the fact that this project was the first VCCE for both instructors, the instructors felt that VCCE meetings should be completed as soon as possible during the semester. This enabled students to concentrate on the written project and other class material during the remainder of the semester. In addition, a later deliverable date allowed students to apply course material to their project. The last student meeting occurred during Week 10 and Week 6 in the United States and Ireland, respectively.

\section{Step 4: VCCE project(s)}

After the last meeting, the students had all the information they needed to complete their deliverables. As shown in Table 1, U.S. students completed three projects whereas Irish students completed one project. This was driven by instructors' individual preferences for course design and their own understanding of their respective classes. Examples of these projects, including feedback from the client and students, are available upon request from the authors.

\section{Implications and suggestions for educators}

\section{Implications for business educators}

Overall, the feedback from the students and the client suggest that VCCEs may be an innovative tool that can provide students with "awesome" experiences not often found in students' real life that also result in high-quality projects which have been used to support resume development (see Table 4). Despite these positive outcomes, the instructors have identified several limitations with VCCE integration. First, we used a VCCE in a context of a semester-long, client-based project. However, all instructors might not be equally excited to use VCCE in such a complex manner. We recommend that instructors experiment with VCCE for the first time by using it as an assignment that can be executed within a shorter time period of 1-2 weeks. Using this approach, they can learn how VCCE works without impacting too much in their existing class structure. This also allows students to enjoy a VCCE in a way that reduces the worry of how long it is and how much it may affect their grade. We also would encourage faculty partners to begin consultation about the project well in advance of the beginning of class. We were fortunate to be the second of two VCCEs supported by a Procter \& Gamble grant (principal investigator: D.J.L.), and as such, we had nearly eight months to prepare for this project as well as learn from the faculty implementing their VCCE the semester prior to our classes.

Second, we found that it was important to keep goals (learning objectives) for each VCCE simple and concrete. For example, asking students to identify the main differences in a product's presentation in local supermarkets 
Table 4. Selected U.S. comments to question "what did you enjoy about working on this project?"

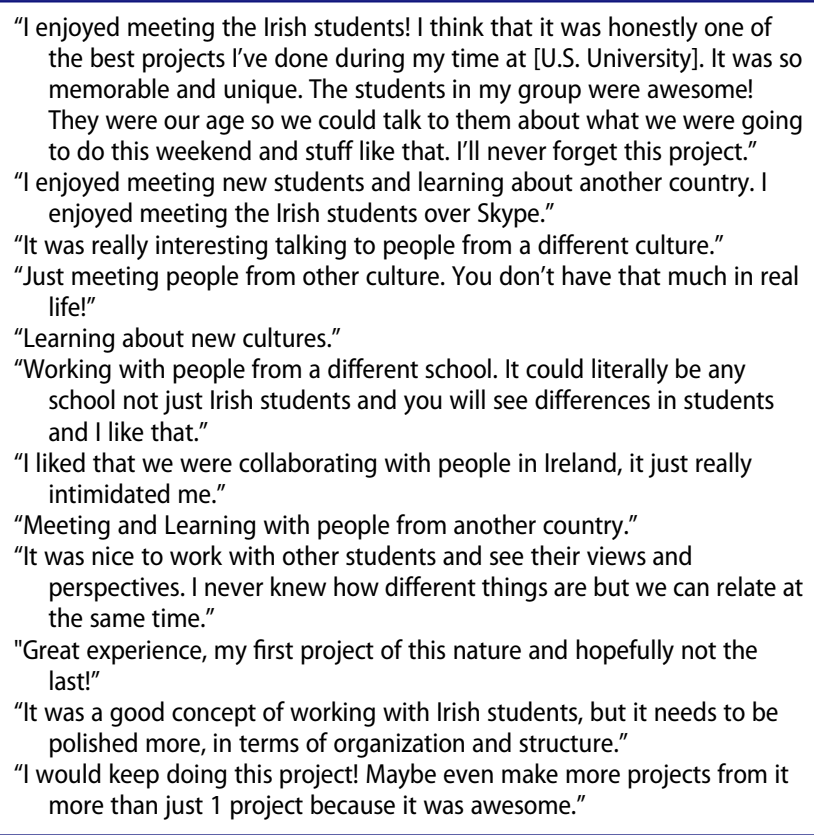

across the two countries is more concrete than asking students to execute a SWOT analysis. As such, the former provides students with a better idea of how to execute such a task and what they need to address when meeting with their foreign counterparts.

Next, we used a VCCE in two classes, each with a different class size. As such, the instructors were challenged with culture-dominated teams (i.e., Irish-dominated teams) in which students who were part of a minority might have felt as if their opinions were not heard and or respected. ${ }^{3}$ Indeed, our results suggest that VCCE experience and its learning effects may depend on cultural dominance and that teams with more equally distributed cultural diversity may further enhance the effects of VCCE. Additionally, from Walther and Bunz's (2005) research on GVT's it may be necessary to provide more order and rules to help minimize the dominance that students perceive. Future research will be needed to examine this fruitful venue of research. Furthermore, the teams were relatively large (about seven students per team), making it challenging for students to meet given their busy lifestyles. Another possible drawback of large teams is the common problem of some team members doing little of the work (i.e., free riders or social loafers). As such, using a VCCE in the context of smaller teams without cultural dominance might be more effective.

We found that the majority of the students preferred to use Skype as it was user-friendly and less complex than WebEx, resulting in the dominance of the Skype platform as a VCCE facilitator. Some students also opted for alternative platforms, such as WhatsApp. Due to its good integration with Facebook and availability on large number of devices such as iPhones, BlackBerries, or Windows Phones, the students found it more convenient. Given these facts, it might be beneficial for educators to present students with a larger set of virtual technology options and to recommend that the students use the one that they and their peers find most useful (i.e., Skype).

Furthermore, we observed that students used Facebook to stay connected with their foreign counterparts, learn more about them, exchange assignment-relevant information, and schedule their VCCE meetings. It might be useful to clearly explain how the social benefits of Facebook could be used in VCCE assignments to further increase the benefits associated with VCCE. In addition, a warm-up, getting-to-know-you exercise that allows students to get to know their foreign team members as well as to practice using their chosen technology can be extremely beneficial.

\section{Future research}

Overall, these limitations and implications serve to facilitate the possibilities for many future research studies. One study is the need for exploration of similar versus different project deliverables (Irish and U.S. students had different deliverables in the study), as well as the impact of single versus multiple web-enabled technology platforms (e.g., WebEx, Skype, Facebook) on students' learning outcome using VCCE. Future researchers could look further into these differences to determine whether one is truly more effective. Also, this research has great potential for rollout across other business schools, and across other disciplines such as finance, global business, human resource management, organizational behavior, and operations management. The approach is easily simplified and easy to replicate, with the core requirement being that of two globally minded instructors who are flexible and open to the requirements of each partner in his or her learning outcomes of the modules. Business graduates who have the experience of working in VCCE have the confidence to discuss this at job interviews as examples of global communication experience which would serve them well if successful in gaining a position in a multicultural organization.

\section{Conclusion}

The importance of integrating cross-cultural experiences that improve students' cultural experience has become a critical component of marketing curriculum, especially in Association to Advance Collegiate Schools of Businessaccredited business colleges. A VCCE provides valuable 
and insightful cross-cultural experiences that aid in such curriculum goals. Additionally, it can serve as a substitute or forerunner opportunity to study abroad programs by increasing students' perceived value of study abroad experiences and interest in other cultures. The method described in this research, the VCCE, provides an alternative venue for by enhancing students' overall learning experience and, at the same time, enhance their ability to effectively communicate and act in culturally diverse environments. Given that a VCCE can be facilitated through a number of low-cost technologies and without the need of travel abroad, VCCEs provide business educators with an innovative tool that has the capacity to improve students' learning experience while allowing them to cross the Atlantic using tools to which they are accustomed (Skype, WhatsApp). Finally, although we see VCCEs as an alternative or a first step for study abroad experiences, they are not a substitute, as the learning one can attain from a longer term immersion in a culture is difficult to replicate. However, VCCEs can act as a legitimate alternative for students who cannot study abroad. We also believe that a VCCE can be a valuable learning experience as a precursor to studying abroad, allowing both students and faculty to dip their toes into international waters prior to actually taking an international plunge.

\section{Notes}

1. We selected WebEx as the primary choice due to its dominant position in the U.S. marketplace. We also opted for using Skype (663+ million users) and WhatsApp (700+ million users) due it is wide availability, low cost, and familiarity to both American and Irish students. Notably, these applications are commonly used by businesses yet sparsely used in classrooms (Strang, 2012), which further encouraged us to integrate them into courses to enhance students' skills.

2. We formed all-Irish groups because the class size in the Irish university was larger and because late student additions to the course in Ireland necessitated this procedure.

3. We also found this to be the case in an earlier VCCE exercise, where American students outnumbered students from the United Kingdom by a ratio of 35:13.

\section{References}

Aistrich, M., Saghafi, M. M., \& Sciglimpaglia, D. (2006). Ivory tower or real world: Do educators and practitioners see the same world? Marketing Education Review, 16(3), 73-80.

Baba, M. L., Gluesing, J., Ratner, H., \& Wagner, K. H. (2004). The contexts of knowing: Natural history of a globally distributed team. Journal of Organizational Behavior, 25, 547587.

Brandl, J., \& Neyer, A. K. (2009). Applying cognitive adjustment theory to cross-cultural training for global virtual teams. Human Resource Management, 48, 341-353.
Cramton, D. D., \& Hinds, P. J. (2014). An embedded model of cultural adaptation in global teams. Organization Science, $25,1056-1081$.

Daim, T. U., Ha, A., Reutiman, S., Hughes, B., Pathak, U., Bynum, W., \& Bhatla, A. (2012). Exploring the communication breakdown in global virtual teams. International Journal of Project Management, 30, 199-212.

Deardorff, D. K. (2006). Identification and assessment of intercultural competence as a student outcome of internationalization. Journal of Studies in International Education, 10, 241-266.

Dekker, D. M., Rutte, C. G., \& Van den Berg, P. T. (2008). Cultural differences in the perception of critical interaction behaviors in global virtual teams. International Journal of Intercultural Relations, 32, 441-452.

Demangeot, C., Adkins, N. R., Mueller, R. D., Henderson, G. R., Ferguson, N. S., Mandiberg, J. M., ... Zúñiga, M. A. (2013). Toward intercultural competency in multicultural marketplaces. Journal of Public Policy \& Marketing, 32, 156-164.

Duus, R., \& Cooray, M. (2014) Together we innovate: Crosscultural teamwork through virtual platforms. Journal of Marketing Education, 36, 244-257.

Erez, M., Lisak, A., Harush, R., Glikson, E., Nouri, R., \& Shokef, E. (2013) Going global: Developing management students' cultural intelligence and global identity in culturally diverse virtual teams. Academy of Management Learning \& Education, 12, 330-355.

Ferreira, P. G. S., Pinheiro de Lima, E., \& Gouvea da Costa, S. E. (2012). Perception of virtual team's performance: A multination exercise. International Journal of Production Economics, 140, 416-430.

Furst, S., Blackburn, R., \& Rosen, B. (2001). Virtual team effectiveness: A proposed research agenda. Information Systems Journal, 9, 249-269.

Hopkins, C. D., Raymond, M. A., \& Carlson, L. (2011). Educating students to give them a sustainable competitive advantage. Journal of Marketing Education, 33, 337-347.

Jarvenpaa, S. L., \& Leidner, D. E. (1999) Communication and trust in global virtual teams. Organization Science, 10, 791815.

Javidan, M. (2013). Comments on the interview: Competencies required for working across borders and managing multicultural teams. Academy of Management Learning \& Education, 12, 506-508.

Johnson, D. M., \& Mader, D. (1992). Internationalizing your marketing course: The foreign study tour alternative. Journal of Marketing Education, 14(2), 26-33.

Klitmøller, A., \& Lauring, J. (2013) When global virtual teams share knowledge: Media richness, cultural difference and language commonality. Journal of World Business, 48, 398406.

Koenig, S. K. (2007). Planning, organizing, and conducting a 2week study abroad trip for undergraduate students: Guidelines for first-time faculty. Journal of Marketing Education, 29, 210-217.

Lopez, T. B., \& Lee, R. G. (2005). Five principles for workable client-based projects: Lessons from the trenches. Journal of Marketing Education, 27, 172-188.

MacNab, B. R. (2012). An experiential approach to cultural intelligence education. Journal of Management Education, $36,66-94$. 
Magnusson, P., Schuster, A., \& Taras, V. (2014). A processbased explanation of the psychic distance paradox: Evidence from global virtual teams. Management International Review, 54, 283-306.

Maznevski, M. (2013). Comments on the interview: Best approaches and practices to increase cultural awareness and prepare managers for working in a culturally diverse environment. Academy of Management Learning \& Education, 12, 509-511.

Mendenhall, M. E., Arnardottir, A. A., Oddou, G. R., \& Burke, L. A. (2013). Developing cross-cultural competencies in management education via cognitive-behavior therapy. Academy of Learning \& Education, 12, 436-451.

Metcalf, L. E. (2013). Creating international community service learning experiences in a capstone marketing projects course. Journal of Marketing Education, 32, 155-171.

Mockaitis, A. I., Rose, E. L., \& Zettinig, P. (2009). The determinants of trust in multicultural global virtual teams. Academy of Management Annual Meeting Proceedings, 2009, 16. doi:10.5465/AMBPP.2009.44243637.

Parsons, A., \& Lepkowska-White, E. (2009). Group projects using clients versus not using clients: Do students perceive any differences. Journal of Marketing Education, 31, 154-159.

Raska, D., Keller, E. W., \& Shaw, D. (2013). Using web-based peer benchmarking to manage the client-based project. Marketing Education Review, 23(1), 23-29.
Rosen, B., Furst, S., \& Blackburn, R. (2007). Overcoming barriers to knowledge sharing in virtual teams. Organizational Dynamics, 36, 259-273.

Shachaf, P. (2008). Cultural diversity and information and communication technology impacts on global virtual teams: An exploratory study. Information and Management, 45, 131-142.

Stahl, G. K., \& Brannen, M. Y. (2013). Building cross-cultural leadership competence: An interview with Carlos Ghosn. Academy of Management Learning \& Education, 12, 494-502.

Stahl, G. K., Maznevski, M. L., Voigt, A., \& Jonsen, K. (2010). Unraveling the effects of cultural diversity in teams: A meta-analysis of research on multicultural work groups. Journal of International Business Studies, 41, 690-709.

Strang, K. D. (2012). Skype synchronous interaction effectiveness in a quantitative management science course. Decision Sciences Journal of Innovative Education, 10, 3-23.

Tanner, J. (2002). Key issues in marketing education. Marketing Education Review, 12, 11.

Taras, V., Caprar, D. V., Ropttig, D., Sarala, R., Zakaria, N., Zhao, F., ... Huang, V. Z. (2013). A global classroom? Evaluating the effectiveness of global virtual collaboration as a teaching tool in management education. Academy of Management Learning \& Education, 12, 414-435.

Walther, J. B., \& Bunz, U. (2005). The rules of virtual groups: Trust, liking and performance in computer-mediated communication. Journal of Communication, 55, 828-846. 